Journal of Clinical Investigation

Vol. 42, No. 9, 1963

\title{
ALTERATIONS IN THE FATTY ACID COMPOSITION OF HUMAN LYMPH AND SERUM LIPOPROTEINS BY SINGLE FEEDINGS *
}

\author{
By HERBERT J. KAYDEN, $\dagger$ ARTHUR KARMEN, AND ALLAN DUMONT
}

(From the Departments of Medicine and Surgery, New York University Medical Center, New York, N. Y., and the Laboratory of Technical Development, National

Heart Institute, Bethesda, Md.)

(Submitted for publication March 4, 1963; accepted May 9, 1963)

Dole and co-workers (1) reported that the fatty acid composition of serum chylomicrons and other serum lipid classes was remarkably stable despite the feeding of fats of widely different composition. Blomstrand ard Dahlbäch (2) analyzed the fatty acid composition of human thoracic duct chyle in two subjects after the feeding of fat formulas and observed that lymph triglycerides closely resembled the pattern of the dietary fat. Cholesterol esters of the chyle were also found to be markedly influenced by the dietary fat, but the FFA and phospholipids were relatively unaffected. Fernandes, van de Kamer, and Weijers (3) studied the pattern of fatty acids in the chyle of a child with chylothorax and observed significant differences between the composition of the fed fat and that of the chylous fluid. Bragdon and Karmen (4) noted that the fatty acid composition of lymph and serum chylomicrons in the rat reflected dietary feeding to a marked extent, and reported that serum chylomicrons in humans also changed to reflect the ingested lipid.

In this study, the acute effect of single feeding of fats on the composition of human thoracic duct lymph and serum has been studied. The thoracic duct chyle and serum were fractionated into 5 lipoprotein classes, and the fatty acid compositions of the lipids were analyzed to study the process of fat absorption and the extent of alterations in lipoprotein composition that occur after feeding of fats of different composition.

* These studies were supported by U. S. Public Health Service grants H 6481 (C1) and H 1913 (C6). Presented in part at the 52nd Annual Meeting of the American Society for Clinical Investigation and American Federation for Clinical Research, April, 1960, Atlantic City, N. J.

† Work done on U. S. Public Health Service research career development award HE-K3-14, 828.

\section{METHODS}

The thoracic duct was cannulated at the level of the supraclavicular space in two subjects. The operation was carried out under local anesthesia, and polyethylene tubing was used to obtain a free flow of lymph as described by Linder and Blomstrand (5). The first patient was a 64-year-old man with inoperable carcinoma of the lung. The second patient was a 54-year-old man with a long history of chronic alcoholism and intermittent bouts of pancreatitis who had a gastrotomy tube at the time of the study. In a third patient, a 39-yearold male convalescing from lobar pneumonia, thoracic duct cannulation was not carried out, and only serum samples were obtained. Cannulation had been carried out in Patient A 2 days and in Patient B 1 day before the day of the study. After an overnight fast, a test meal of $100 \mathrm{~g}$ of corn oil or coconut oil mixed in $250 \mathrm{ml}$ of fruit juice was given. Chyle was continuously collected, and blood samples were taken intermittently for the subsequent 48 hours. Clear fluids and fruit juices were permitted for 8 hours after the test meal, and the patient was then allowed to have his regular diet. No attempt was made to control the dietary intake of the patients before or during the study. At the end of the study period, the cannula was withdrawn, and normal lymph flow re-established without difficulty.

The lymph was strained through gauze to remove fibrin strands. Suitable samples were layered under buffered saline, $\mathrm{pH} 7.4$ (.01 $\mathrm{M}$ sodium phosphate with $.05 \%$ disodium salt of ethylenediaminetetraäcetic acid) and spun in the Model $\mathrm{L}$ Spinco centrifuge at $26,000 \times g$ for 30 minutes at room temperature. The chylomicrons were concentrated into a thick layer at the top of the tube: they were removed from the lusteroid tube by a tube slicer and capillary pipettes. The chylomicrons were emulsified in buffered saline by repeated drawing through a fine needle. The suspended chylomicrons were again separated in the ultracentrifuge at the same gravitational field. This procedure of emulsification and centrifugation was repeated 3 times. The infranatant fluids of the washed chylomicrons were discarded. Higher density lipoprotein fractions of the lymph were obtained by successive ultracentrifugation of the original infranatant fluid at $105,000 \times g$ for 20 hours at specific gravities of 1.019, 1.063, and for certain studies 1.21, with potassium bromide in appropriate concentration to 
obtain the desired specific gravity. Serum samples were handled in similar fashion. Although no layering developed in the tube during the initial spin of the fasting serum samples, the top fractions were removed and washed by being suspended in buffered saline and centrifuged twice without emulsification.

The lipids were extracted from lipoproteins by a modified Folch procedure using chloroform and methanol, $2: 1, \mathrm{vol} / \mathrm{vol}$, and washing this extract with water (6). The chloroform extracts were dried in vacuo and reextracted into chloroform. Samples were taken for the individual lipid analyses as well as for the preparation of methyl esters for gas chromatography. Separation of cholesterol esters, triglycerides, cholesterol, and phospholipids was carried out by silicic acid column chromatography in stages as follows: Activated silicic acid 1 to $2 \mathrm{~g}$, prepared according to the method of Sweeley and Moscatelli (7), was made into a slurry with chloroform methanol, $4: 1$, vol/vol, and poured to form a column $7 \mathrm{~mm}$ wide. The column was washed with pure chloroform, and the sample (in chloroform) was placed on the column. The initial eluant was $20 \mathrm{ml}$ of $100 \%$ chloroform. This eluate contained cholesterol esters, triglycerides, and free cholesterol. This fraction was evaporated under nitrogen and re-extracted into petroleum ether (bp, $60^{\circ}$ to $62^{\circ} \mathrm{C}$ ). The petroleum ether extract of the initial eluate ( $100 \%$ chloroform) was rechromatographed on a column of silicic acid supercel in the ratio of $1: 1$, with nonactivated silicic acid. The slurry was made with chloroform, poured into a syringe barrel, and washed with petroleum ether. Cholesterol esters were eluted with $10 \%$ chloroform in petroleum ether, and triglycerides with $100 \%$ chloroform as described by Van Handel and Zilversmit (8).

The lipid fractions were then dried under a stream of nitrogen. Methyl esters of the fatty acids were prepared by incubating these extracts at $65^{\circ} \mathrm{C}$ with $1 \mathrm{ml}$ of a mixture of $98 \%$ methanol and $2 \%$ sulfuric acid in a sealed tube for 16 hours. Five $\mathrm{ml}$ of water was then added to each tube, and the lipids were extracted into petroleum ether. The petroleum ether extracts were carefully dried by using nitrogen, isooctane was added,

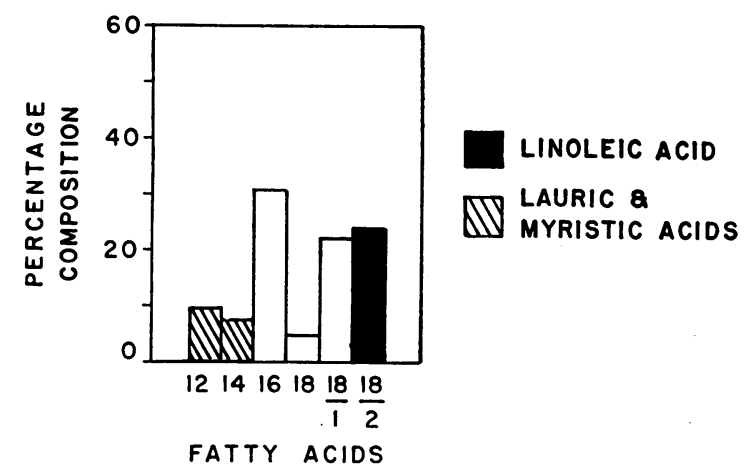

Fig. 1. Percentage of fatty acid composition of HUMAN THORACIC DUCT LYMPH CHYLOMICRONS IN THE fasting state. Patient A.
TABLE I

Fatty acid composition of human thoracic duct lymph lipoproteins in the fasting state and after corn oil feeding*

\begin{tabular}{|c|c|c|c|c|c|c|}
\hline \multirow[b]{2}{*}{$\begin{array}{l}\text { Density } \\
\text { class }\end{array}$} & \multirow[b]{2}{*}{$\begin{array}{c}\text { Carbon } \\
\text { no. }\end{array}$} & \multirow[b]{2}{*}{$\begin{array}{c}\text { Fast- } \\
\text { ing }\end{array}$} & \multicolumn{4}{|c|}{ After corn oil } \\
\hline & & & $\begin{array}{l}2-4 \\
\text { hrs }\end{array}$ & $\begin{array}{l}8-10 \\
\text { hrs }\end{array}$ & $\begin{array}{c}11-23 \\
\text { hrs }\end{array}$ & $\begin{array}{c}35-47 \\
\text { hrs }\end{array}$ \\
\hline \multirow[t]{7}{*}{$<1.005$} & $10: 0$ & 2 & 0 & $\mathbf{0}$ & $\mathbf{0}$ & 0 \\
\hline & $12: 0$ & 3 & 0 & 0 & 0 & 2 \\
\hline & $14: 0$ & 10 & 1 & $\mathbf{0}$ & $\mathbf{0}$ & 4 \\
\hline & $16: 0$ & 37 & 16 & 10 & 14 & 29 \\
\hline & $18: 0$ & 8 & 3 & 1 & 3 & 8 \\
\hline & $18: 1$ & 32 & 31 & 26 & 34 & 38 \\
\hline & $18: 2$ & 8 & 49 & 63 & 49 & 19 \\
\hline \multirow[t]{7}{*}{$1.005-1.019$} & 10:0 & 1 & 1. & o & $\mathbf{0}$ & $\mathbf{0}$ \\
\hline & $12: 0$ & 1 & 1 & o & $\mathbf{0}$ & 1 \\
\hline & 14:0 & 5 & 0 & 1 & 1 & 2 \\
\hline & $16: 0$ & 32 & 21 & 16 & 16 & 32 \\
\hline & $18: 0$ & 14 & 6 & 4 & 6 & 10 \\
\hline & 18:1 & 35 & 31 & 37 & 33 & 35 \\
\hline & $18: 2$ & 12 & 40 & 42 & 44 & 20 \\
\hline \multirow[t]{7}{*}{$1.019-1.063$} & 10:0 & $\mathbf{0}$ & 0 & $\mathbf{0}$ & $\mathbf{0}$ & $\mathbf{0}$ \\
\hline & $12: 0$ & 1 & 1 & o & 0 & 1 \\
\hline & $14: 0$ & 1 & 1 & 1 & 1 & 1 \\
\hline & $16: 0$ & 26 & 27 & 25 & 24 & 26 \\
\hline & $18: 0$ & 7 & 6 & 5 & 6 & 8 \\
\hline & 18:1 & 36 & 27 & 27 & 31 & 35 \\
\hline & $18: 2$ & 29 & 38 & 42 & 38 & 29 \\
\hline \multirow[t]{7}{*}{$>1.063$} & 10:0 & 1 & 0 & 0 & $\mathbf{0}$ & 0 \\
\hline & $12: 0$ & 2 & 1 & 0 & 0 & 1 \\
\hline & $14: 0$ & 5 & 1 & 1 & 1 & 2 \\
\hline & $16: 0$ & 26 & 20 & 18 & 18 & 31 \\
\hline & 18:0 & 8 & 5 & 4 & 5 & 9 \\
\hline & $18: 1$ & 38 & 29 & 26 & 28 & 31 \\
\hline & $18: 2$ & 20 & 44 & 51 & 48 & 26 \\
\hline
\end{tabular}

$61 \%$.

and samples of the isooctane solution, 2 to $3 \mu 1$, were used for gas-liquid chromatography. Gas-liquid chromatography columns were 6 feet long and filled with Chromosorb-W ${ }^{1}$ coated with an ethylene glycol, adipate, polyester coating approximately $10 \%$ of the weight of the Chromosorb. The column temperature was $196^{\circ} \mathrm{C}$. The detector was a modified argon ionization detector (9). The detector system was calibrated for quantitative accuracy by analyzing serial dilutions of the methyl esters of corn oil in isooctane. To minimize the effect of small differences in the relative response of the detector for the different fatty acid esters, and to facilitate comparison, fractions obtained from each experiment were analyzed on the same column consecutively. The components of the mixture were identified by comparing retention times with those of known fatty acid esters. ${ }^{2}$

Gas-liquid chromatography was carried out through the 18-carbon fatty acid esters. The quantity of longerchain fatty acids present represented relatively small fractions of the total and did not materially affect the results. Neither diet contained fatty acids longer than 18 carbons.

${ }^{1}$ Johns-Manville Co., New York, N. Y.

2 Obtained from The Hormel Institute, Austin, Minn. 


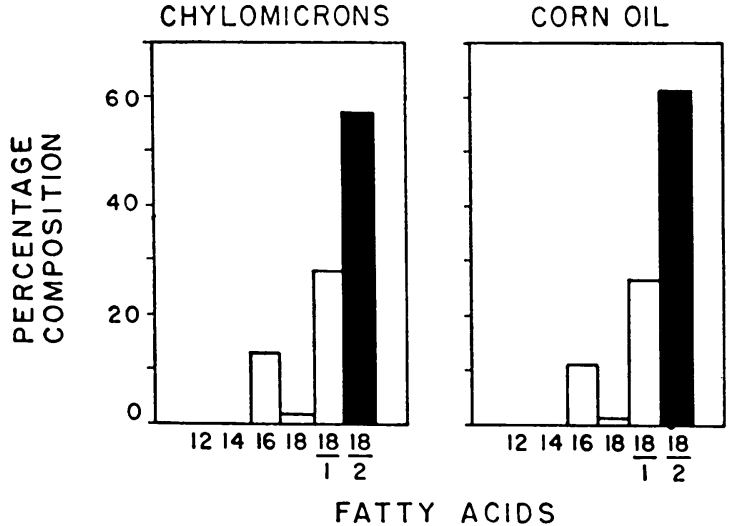

Fig. 2. FatTy acid COMPOSITION OF HUMAN THORACIC DUCT LYMPH CHYLOMICRONS AFTER CORN OIL FEEDINGS AND THE FATTY ACID COMPOSITION OF CORN oIl. Patient A.

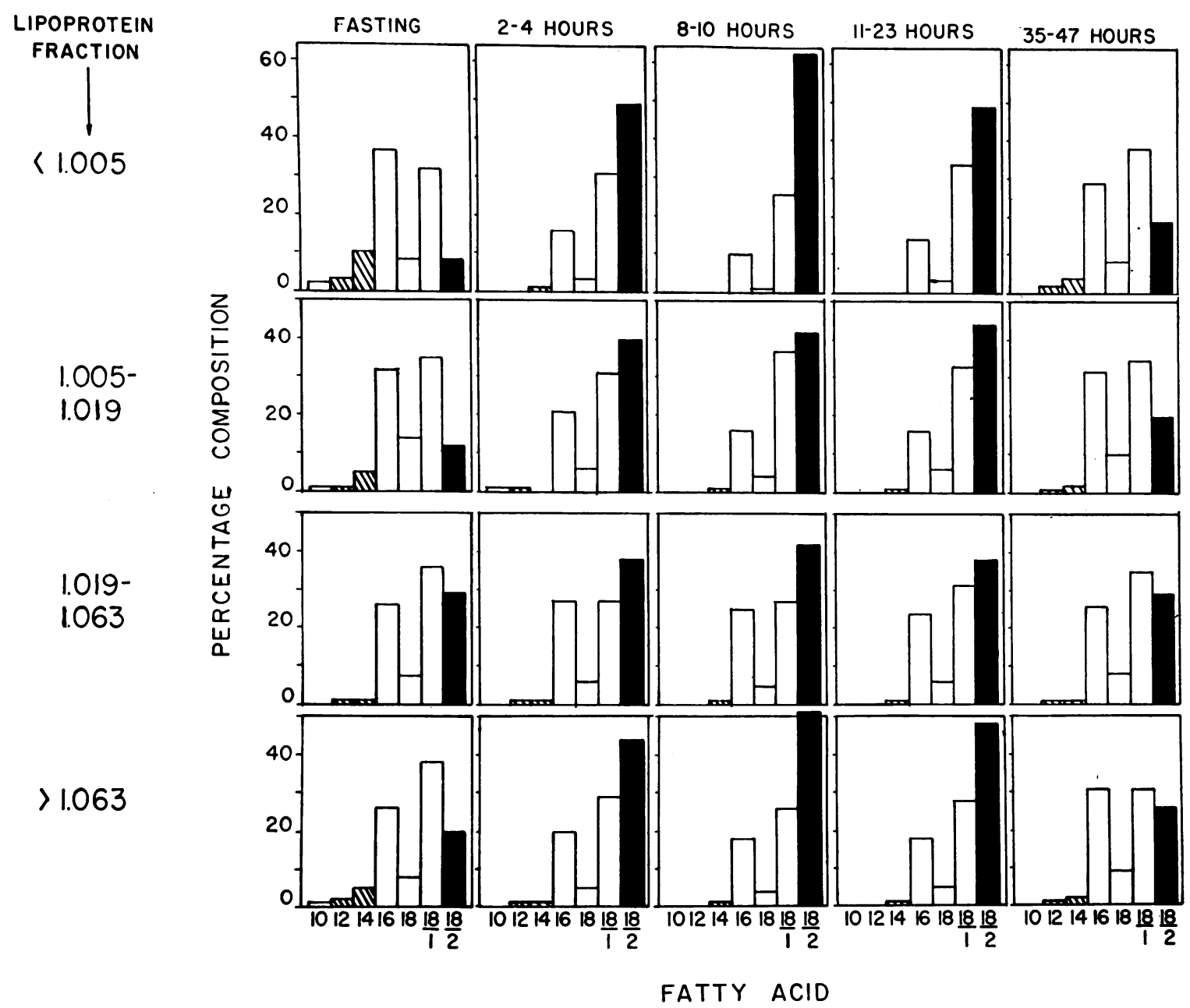

Fig. 4. Fatty acid composition of human thoracic duCt lymph lipoproteins after 100 g corn oil. Patient B. 
RESULTS

The fatty acid composition of the lymph chylomicrons of Patient A after an overnight fast is shown in Figure 1. The major components are $31 \%$ palmitic acid $(16: 0), 22 \%$ oleic acid (18:1), and $24 \%$ linoleic acid $(18: 2)$. Figure 2 compares the composition of lymph chylomicrons in thoracic duct chyle 8 hours after 100 -g corn oil feeding with the composition of corn oil itself. This highly unsaturated oil was found to be composed of $11 \%$ palmitic acid, $27 \%$ oleic acid, and $61 \%$ linoleic acid. The gas chromatographic patterns of the chylomicrons and of corn oil are almost identical. The lymph sample 24 hours after the original feeding was still identical with that of corn oil. At this time, $100 \mathrm{~g}$ of coconut oil, a highly saturated oil containing predominantly fatty acids 10:0 (9\%), 12:0 (61\%), 14:0
$(20 \%)$, and 16:0 (7\%) was given. Figure 3 shows the fatty acid composition of the chylomicrons of chyle 8 hours after coconut oil feeding and of coconut oil itself. The lower concentration of 10:0 saturated fatty acid in thoracic duct chyle agrees with the observations that shorterchain fatty acids are absorbed directly into the portal system. The appearance of lauric and myristic acids was first noted about 2 hours after ingestion of the coconut oil.

In Patient $\mathrm{B}$, the lymph was continuously collected for a 48-hour period after the administration of $100 \mathrm{~g}$ of corn oil by gastrotomy tube. The patient had fasted for 12 hours before ingestion of corn oil and did not receive any food until after the 10-hour collection. The gas-liquid chromatographic analysis of the fatty acids in the total lipid extracts of the lymph lipoprotein fractions-i.e., the chylomicrons, density classes 1.005

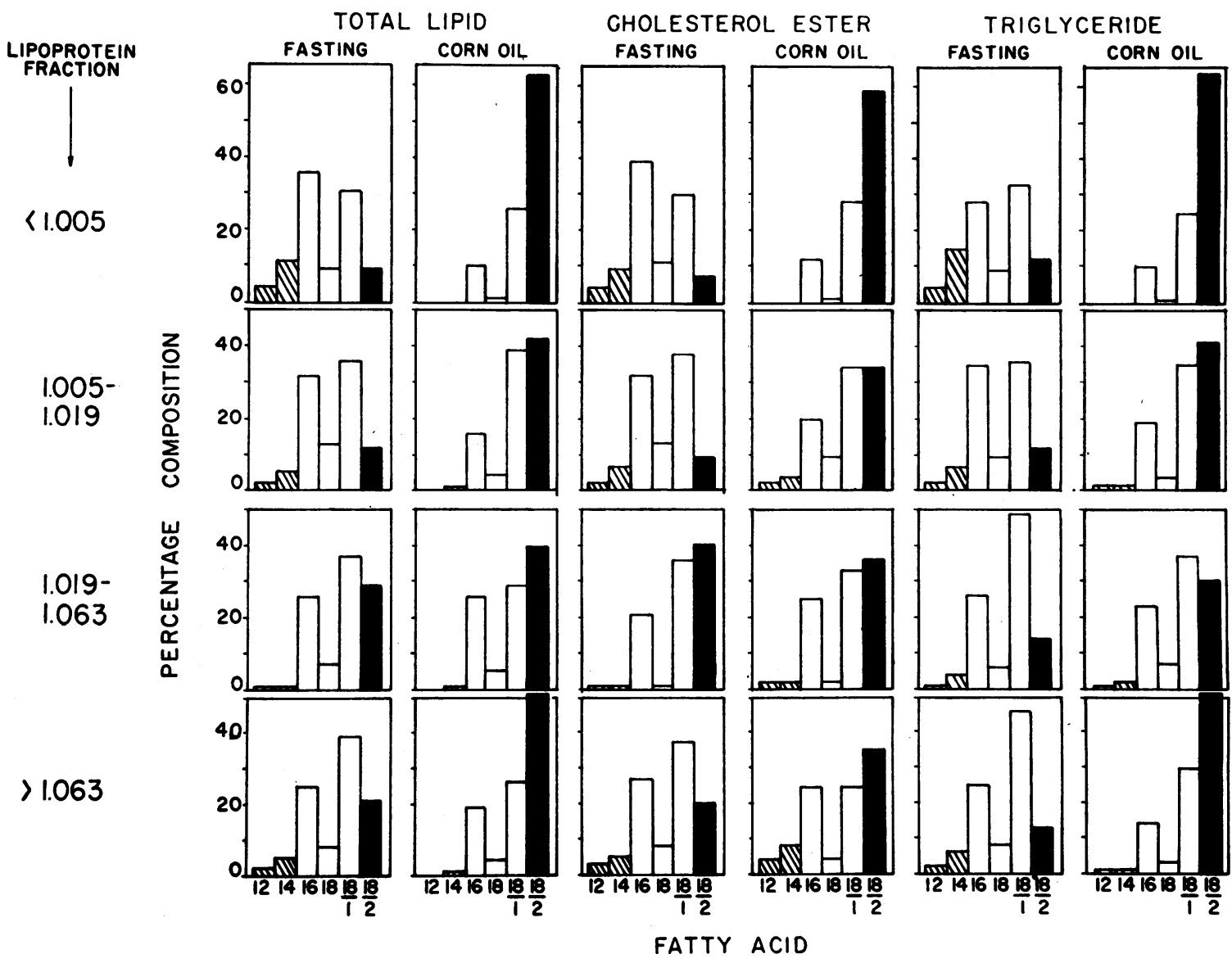

Fig. 5. FATty ACID COMPosition OF TOTAL LIPID EXTRACTS OF HUMAN THORACIC DUCT CHYLE LIPOPROTEINS AND OF THEIR CHOLESTEROL ESTER AND TRIGLYCERIDE FRACTIONS IN FASTING STATE AND 8 to 10 HOURS AFTFR 100 g CORN OH. Patient B. 


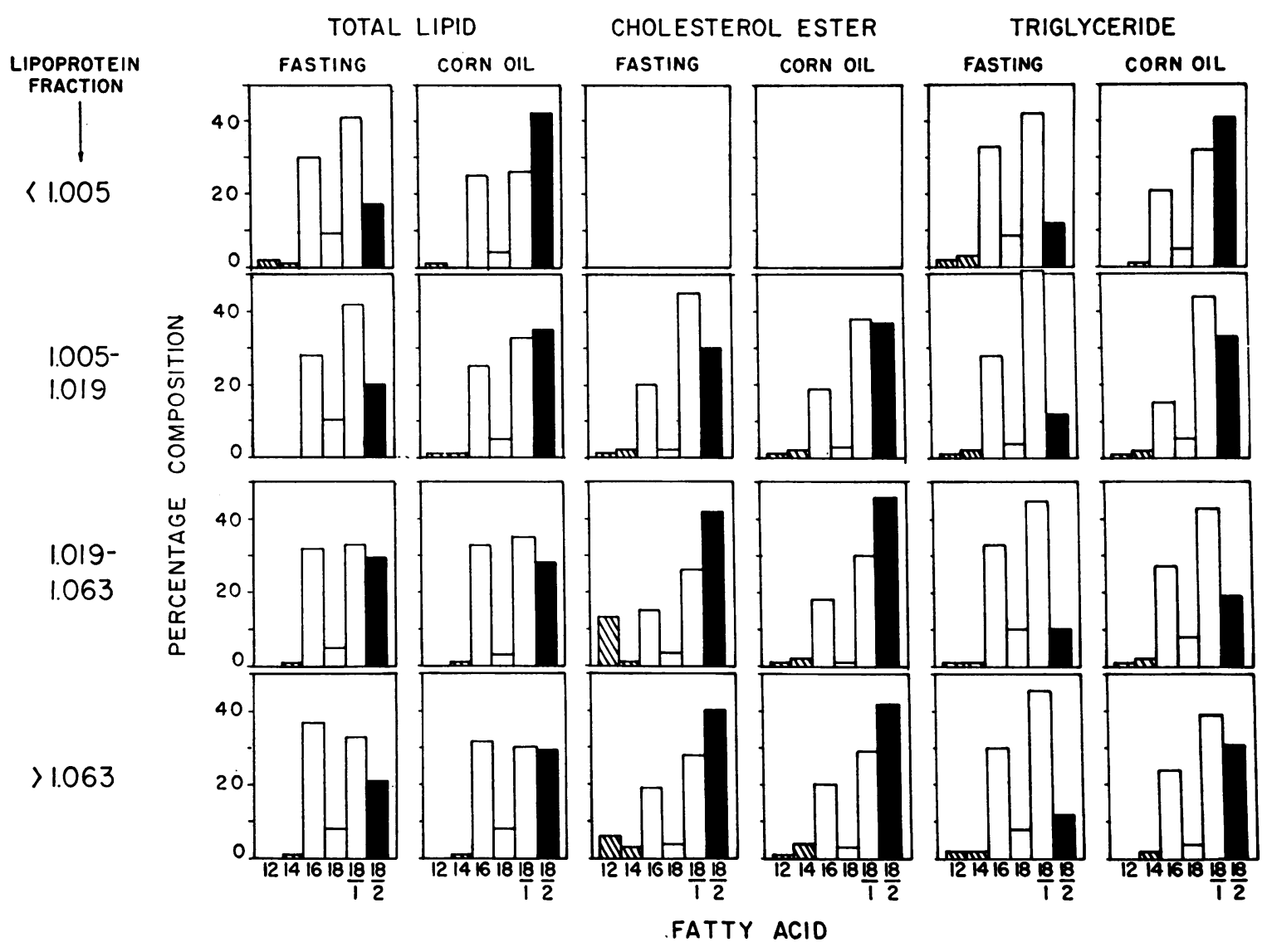

Fig. 6. FATTY ACID COMPOSITION OF TOTAL LIPID EXTRACTS OF HUMAN SERUM LIPOPROTEINS AND OF THEIR CHOLESTEROL ESTER AND TRIGLYCERIDE FRACTIONS IN THE FASTING STATE AND 8 hOURS AFTER 100 g OF CORN OIL. Patient B.

to $1.019,1.019$ to 1.063 , and greater than 1.063 is depicted in Figure 4 and Table I. The successive panels in the figure represent the composition of the fasting lymph and the specimens collected 2 to 4 hours, 8 to 10 hours, 11 to 23 hours, and 35 to 47 hours after the corn oil feeding. The relative concentration of linoleic acid, the solid bar, is increased in each of the lipoprotein classes, but the maximal concentration reached during the 48-hour collection period was different in each lipoprotein class. The chylomicron fraction contained $63 \%$ linoleic acid, but in the other lipoprotein fractions the peak levels of linoleic acid are only 44 to $51 \%$ of the total fatty acids in each fraction. At the end of the 48-hour collection period, the composition of the chylomicrons and other lipoproteins was similar to the values obtained during the fasting state, except for an increase in linoleic acid concentration of from 6 to $11 \%$.
The lipoprotein fractions of the lymph collection of the 8- to 10-hour period after ingestion of corn oil were separated into cholesterol ester, triglyceride, and phospholipid fractions. In Figure 5 the fatty acid composition of the whole lipid extract and of the constituent cholesterol ester and triglyceride fraction is shown. The composition of the cholesterol ester fraction of the various lipoproteins varied. The linoleic acid content of the cholesterol ester fraction in the fasting state was $7 \%$ and $9 \%$ in the chylomicron and 1.005 to 1.019 classes, respectively, but made up $41 \%$ of the 1.019 to 1.063 class. Cholesterol ester represents from 3 to $6 \%$ of the total lipid weight in the lipoprotein fractions of fasting chyle. The chylomicron fraction of lymph after a test meal contained about $90 \%$ of the total lipid of the lymph.

The fatty acid distribution of both the cholesterol ester and triglyceride moieties in the lipo- 
proteins of the 1.019 to 1.063 density class of lymph showed little change after the ingestion of corn oil, i.e., despite linoleic acil concentration of $61 \%$ and oleic acid concentration of $27 \%$ in corn oil, the oleic acid percentage in triglyceride fraction fell to $37 \%$, and linoleic acid concentration rose to only $30 \%$. In contrast, the changes in the cholesterol ester and triglyceride fractions of the high density lipoprotein with respect to linoleic acid were from 20 to $35 \%$ and from 13 to $51 \%$.

In Patient $\mathrm{B}$, the thoracic duct cannula was withdrawn 24 hours after the corn oil study, and normal drainage re-established into the venous system. A coconut oil test meal was given by gastrotomy tube, and blood samples were drawn at specified intervals. Two days later, the corn oil feeding was repeated, and blood samples were drawn.

The fatty acid composition of serum lipopro- teins in the fasting state and 8 hours after $100 \mathrm{~g}$ of corn oil is shown in the firs: two panels of Figure 6, and after $100 \mathrm{~g}$ of coconut oil in the first two panels of Figure 7. The fatty acid composition of the total lipid extract of the serum lipoprotein fraction $\mathrm{d}<1.005$, "serum chylomicrons," resembles the dietary fat to a lesser extent than the thoracic duct chylomicrons. The relative insensitivity of the composition of the lipoprotein class 1.019 to 1.063 to either the coconut or corn oil feeding is reflected by the uniformity of fatty acid distribution in all four samples. There are changes in fatty acid distribution in the fraction 1.063 to 1.21 , but these are not so striking as those seen in the less than 1.005 or 1.005 to 1.019 fraction.

The numerical values for the percentage distribution of the fatty acids of the cholesterol ester and triglyceride fractions of each class of serum lipoproteins in the fasting state and after corn and

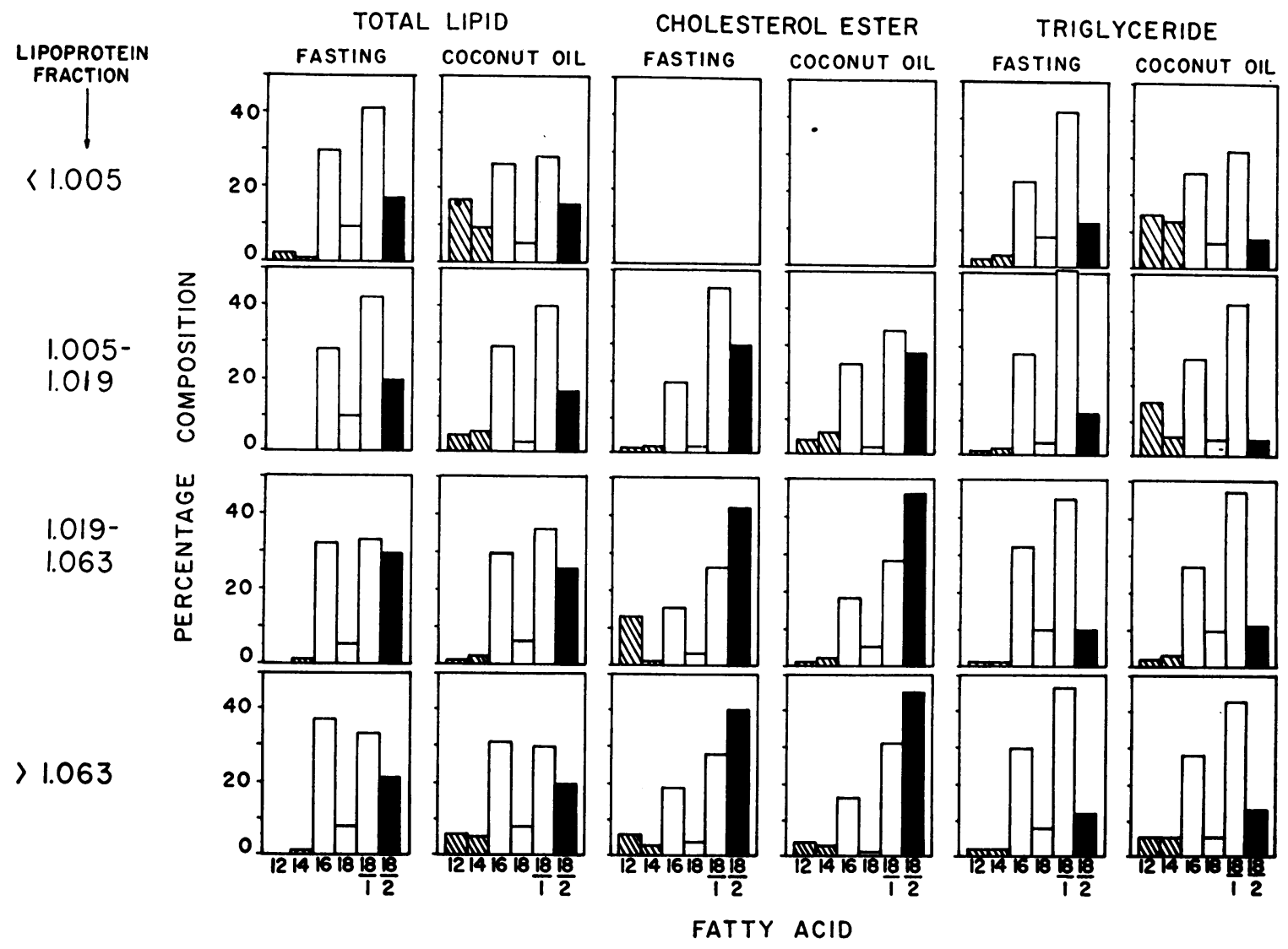

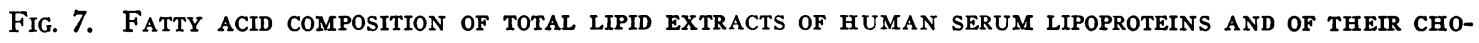
LESTEROL. ESTER AND TRIGLYCERIDE FRACTIONS IN THE FASTING STATE AND 8 HOURS AFTER 100 g OF COCONUT OIL. Patient B. 
TABLE II

Fatty acid composition of total lipid extract of human serum lipoproteins and their cholesterol ester and triglyceride fractions*

\begin{tabular}{|c|c|c|c|c|c|c|c|c|c|c|}
\hline \multirow[b]{2}{*}{ Density class } & \multirow[b]{2}{*}{$\begin{array}{c}\text { Carbon } \\
\text { no. }\end{array}$} & \multicolumn{3}{|c|}{ Total lipid } & \multicolumn{3}{|c|}{ Cholesterol ester } & \multicolumn{3}{|c|}{ Triglyceride } \\
\hline & & $\begin{array}{c}\text { Fast- } \\
\text { ing }\end{array}$ & $\begin{array}{l}\text { After } \\
\text { corn } \\
\text { oil }\end{array}$ & $\underset{\substack{\text { After } \\
\text { coconut } \\
\text { oil }}}{ }$ & $\begin{array}{c}\text { Fast- } \\
\text { ing }\end{array}$ & $\begin{array}{c}\text { After } \\
\text { corn } \\
\text { oil }\end{array}$ & $\underset{\substack{\text { After } \\
\text { coconut } \\
\text { oil }}}{ }$ & $\begin{array}{c}\text { Fast- } \\
\text { ing }\end{array}$ & $\begin{array}{l}\text { After } \\
\text { corn } \\
\text { oil }\end{array}$ & $\begin{array}{c}\text { After } \\
\text { coconut } \\
\text { oil }\end{array}$ \\
\hline$<1.005$ & $\begin{array}{l}12: 0 \\
14: 0 \\
16: 0 \\
18: 0 \\
18: 1 \\
18: 2\end{array}$ & $\begin{array}{r}2 \\
1 \\
30 \\
9 \\
41 \\
17\end{array}$ & $\begin{array}{r}1 \\
0 \\
25 \\
4 \\
26 \\
42\end{array}$ & $\begin{array}{r}17 \\
9 \\
26 \\
5 \\
28 \\
16\end{array}$ & & & & $\begin{array}{r}2 \\
3 \\
33 \\
8 \\
42 \\
12\end{array}$ & $\begin{array}{r}0 \\
1 \\
21 \\
5 \\
32 \\
41\end{array}$ & $\begin{array}{r}15 \\
12 \\
26 \\
7 \\
32 \\
8\end{array}$ \\
\hline $1.005-1.019$ & $\begin{array}{l}12: 0 \\
14: 0 \\
16: 0 \\
18: 0 \\
18: 1 \\
18: 2\end{array}$ & $\begin{array}{r}0 \\
0 \\
28 \\
10 \\
42 \\
20\end{array}$ & $\begin{array}{r}1 \\
1 \\
25 \\
5 \\
33 \\
35\end{array}$ & $\begin{array}{r}5 \\
6 \\
29 \\
3 \\
40 \\
17\end{array}$ & $\begin{array}{r}1 \\
2 \\
20 \\
2 \\
45 \\
30\end{array}$ & $\begin{array}{r}1 \\
2 \\
19 \\
3 \\
38 \\
37\end{array}$ & $\begin{array}{r}5 \\
7 \\
25 \\
2 \\
34 \\
28\end{array}$ & $\begin{array}{r}1 \\
2 \\
28 \\
4 \\
53 \\
12\end{array}$ & $\begin{array}{r}1 \\
2 \\
15 \\
5 \\
44 \\
33\end{array}$ & $\begin{array}{r}15 \\
6 \\
27 \\
5 \\
42 \\
5\end{array}$ \\
\hline $1.019-1.063$ & $\begin{array}{l}12: 0 \\
14: 0 \\
16: 0 \\
18: 0 \\
18: 1 \\
18: 2\end{array}$ & $\begin{array}{r}0 \\
1 \\
32 \\
5 \\
33 \\
29\end{array}$ & $\begin{array}{r}0 \\
1 \\
33 \\
3 \\
35 \\
28\end{array}$ & $\begin{array}{r}1 \\
2 \\
30 \\
6 \\
36 \\
25\end{array}$ & $\begin{array}{r}2 \\
1 \\
18 \\
3 \\
33 \\
42\end{array}$ & $\begin{array}{r}1 \\
2 \\
18 \\
1 \\
30 \\
46\end{array}$ & $\begin{array}{r}1 \\
2 \\
18 \\
5 \\
28 \\
46\end{array}$ & $\begin{array}{r}1 \\
1 \\
33 \\
10 \\
45 \\
10\end{array}$ & $\begin{array}{r}1 \\
2 \\
27 \\
8 \\
43 \\
19\end{array}$ & $\begin{array}{r}2 \\
3 \\
27 \\
10 \\
47 \\
11\end{array}$ \\
\hline$>1.063$ & $\begin{array}{l}12: 0 \\
14: 0 \\
16: 0 \\
18: 0 \\
18: 1 \\
18: 2\end{array}$ & $\begin{array}{r}0 \\
1 \\
37 \\
8 \\
33 \\
21\end{array}$ & $\begin{array}{r}0 \\
1 \\
32 \\
8 \\
30 \\
29\end{array}$ & $\begin{array}{r}6 \\
5 \\
31 \\
8 \\
30 \\
20\end{array}$ & $\begin{array}{r}6 \\
3 \\
19 \\
4 \\
28 \\
40\end{array}$ & $\begin{array}{r}1 \\
4 \\
20 \\
3 \\
29 \\
43\end{array}$ & $\begin{array}{r}4 \\
3 \\
16 \\
1 \\
31 \\
45\end{array}$ & $\begin{array}{r}2 \\
2 \\
30 \\
8 \\
46 \\
12\end{array}$ & $\begin{array}{r}0 \\
2 \\
24 \\
4 \\
39 \\
31\end{array}$ & $\begin{array}{r}6 \\
6 \\
28 \\
5 \\
42 \\
13\end{array}$ \\
\hline
\end{tabular}

* Fatty acid composition of corn oil-16:0,11\%;18:1,27\%;18:2,61\%. Coconut oil-10:0,9\%;12:0,61\%;14:0, $20 \% ; 16: 0,7 \%$.

coconut oil are given in Table II. The distribution is shown graphically in the last four panels of Figures 6 and 7 . The changes in the fatty acid composition of the triglycerides appear to vary from density class to density class. The triglycerides of the 1.019 to 1.063 class showed less change after either corn oil or coconut oil than did the triglycerides isolated from the 1.005 to 1.019 class. The cholesterol ester fraction of each lipoprotein class was much less subject to change after dietary feeding than was the triglyceride fraction, but the changes that did occur were of a different extent in each lipoprotein class.

The third patient, Patient $\mathrm{C}$, received a corn and a coconut oil test meal, and only serial blood samples were drawn. The changes in the fatty acid composition of his lipoprotein fractions were similar to those found in Patient B.

\section{DISCUSSION}

Chylomicrons, the least dense class of lipoproteins, are harvested from serum or chyle and purified by several washings and centrifugation at specific gravity 1.005 . In the studies described here, human chyle chylomicrons 6 to 8 hours following the feeding of a fat meal have been shown to have a fatty acid composition similar to that of the fatty meal. The chylomicron fraction is not alone in this respect, since the fatty acid composition of other fractions of the chyle separated by ultracentrifugation also changes to resemble the fatty meal fed. Quantitatively, the changes in the classes other than chylomicrons were most marked in the 1.005 to 1.019 specific gravity class and in the high density 1.063 to 1.21 lipoprotein class. The changes in these fractions were neither so marked nor was the amount of fat contained so high that it would be reasonable to conclude that these fractions carry a large portion of recently ingested fat in the chyle.

Although the composition of the lymph chylomicrons after the fatty meal eventually ( 6 to 8 hours after ingestion) became identical with that of the meal, in the early postprandial state ( 2 to 4 
hours and 4 to 6 hours) after the fat content of the chyle had already increased, the fatty acid composition of the chylomicrons did not completely resemble that of the fed fat. It was also apparent that 10 to 12 hours after the meal, even though the fat content of the lymph was still markedly elevated above that of the fasting sample, the fatty acid composition was once again different from that of the meal. The chylomicrons during the early and late postprandial periods were composed of the same fatty acids as were in the fat meal, but in different relative proportions, and also of fatty acids not in the test meal. A1though the presence of different amounts of the same fatty acids as in the meal might represent selective or sequential absorption of these fatty acids, the presence of the other fatty acids strongly suggests a contribution to the lymph chylomicrons from a source within the organism. It is possible that the intestinal mucosa may synthesize chylomicrons from circulating plasma lipids as well as from the dietary fat in the lumen.

The lymph collected from the thoracic duct cannula is composed of lymph from other sources as well as the intestine. Hepatic lymph enters the main abdominal lymph channel at the level of the cisterna chyle, where it becomes the main thoracic duct. The contribution of hepatic lymph to the thoracic duct lymph may be appreciable. In hepatic cirrhosis, the thoracic duct lymph flow rate may reach $10 \mathrm{ml}$ per minute, the major contribution being from hepatic lymph (10). The liver is the major organ for synthesis of all plasma lipoproteins, and these lipoproteins are also present in the thoracic duct lymph. It may well be that the stability in fatty acid composition of the lowdensity lipoproteins (1.019 to 1.063) observed during these fat absorption studies reflects the continuing synthesis of these lipoproteins from lipid sources other than the newly absorbed fat. On the other hand, the change in fatty acid composition of the other lipoprotein classes (1.005 to 1.019 and 1.063 to 1.21 ) may reflect the incorporation of newly absorbed fatty acids into the lipoproteins in the intestine.

The fractionation of the lipoproteins into their constituent lipids of triglycerides, cholesterol esters, and phospholipids was carried out by silicic acid column chromatography. The fatty acid composition of each of these lipids in each lipo- protein class was altered to a different extent. The triglyceride fraction in each lipoprotein class showed the greatest change for that class, with the phospholipids and cholesterol esters showing lesser but definite changes. These variations in the changes of each of the lipids in the lipoprotein classes as well as within a given lipoprotein group imply that each lipid (triglyceride, cholesterol ester, phospholipid, etc.) is synthesized by a different mechanism with a different specificity during the process of absorption, or that they are the results of a mixing of lipids from different sources, or both. At the peak of absorption, the triglyceride content of the chylomicrons so closely resembled the fed fat that the effect of contribution of fat from other sources may be masked. In other lipids, the effect of dietary fat is less prominent, and the increase in lipid cannot be ascribed solely to the diet.

\section{SUMMARY}

1) The fatty acid composition of human thoracic duct chyle lipoproteins has been analyzed by gasliquid chromatography in two men in the fasting state and after the feeding of a highly unsaturated oil, corn oil, and after the feeding of a highly saturated oil, coconut oil. Serum lipoproteins have also been studied in similar fashion in two subjects.

2) The fatty acid composition of thoracic duct chylomicrons was almost identical with that of the test meal 6 to 8 hours after ingestion.

3) Serum lipoproteins $d<1.005$, "chylomicrons," also reflected the composition of the test meal, but the change in composition was not so complete as that observed in thoracic duct chylomicrons.

4) Other lymph and serum lipoprotein classes also showed alterations in composition after the single test meal. The density class 1.019 to 1.063 was the most stable group of the lipoprotein classes.

5) Within each density class, the triglycerides were altered to the greatest extent, with less change noted in the cholesterol ester fraction.

\section{REFERENCES}

1. Dole, V. P., A. T. James, J. P. W. Webb, M. A. Rizack, and M. F. Sturman. The fatty acid patterns of plasma lipids during alimentary lipemia. J. clin. Invest. 1959, 38, 1544. 
2. Blomstrand, R., and O. Dahlbäch. The fatty acid composition of human thoracic duct lymph lipids. J. clin. Invest. 1960, 39, 1185.

3. Fernandes, J., J. H. van de Kamer, and H. A. Weijers. The absorption of fats studied in a child with chylothorax. J. clin. Invest. 1955, 24, 1026.

4. Bragdon, J. H., and A. Karmen. The fatty acid composition of chylomicrons of chyle and serum following the ingestion of different oils. J. Lipid Res. 1960, 1, 167.

5. Linder, E., and R. Blomstrand. Technic for collection of thoracic duct lymph of man. Proc. Soc. exp. Biol. (N. Y.) 1958, 97, 653.
6. Folch, J., I. Ascoli, M. Lees, J. A. Meath, and F. N. LeBaron. Preparation of lipide extracts from brain tissue. J. biol. Chem. 1951, 191, 833.

7. Sweeley, C. C., and E. A. Moscatelli. Qualitative microanalysis and estimation of sphingolipid bases. J. Lipid Res. 1960, 1, 40.

8. Van Handel, E., and D. B. Zilversmit. Micromethod for the direct determination of serum triglycerides. J. Lab. clin. Med. 1957, 50, 152.

9. Lovelock, J. A sensitive detector for gas chromatography. J. Chrom. 1958, 1, 35.

10. Dumont, A., and J. H. Mulholland. Flow rate and composition of thoracic-duct lymph in patients with cirrhosis. New Engl. J. Med. 1960, 263, 471.

\section{SPECIAL NOTICE TO SUBSCRIBERS}

Post Offices will no longer forward the Journal when you move.

Please notify The Journal of Clinical Investigation, Business Office, 10 Stoughton Street, Boston 18, Mass., at once when you have a change of address, and do not omit the zone number if there is one. 